\title{
Student decision making about a globally familiar socioscientific issue: The value of sharing and comparing views with international counterparts
}

Marcus Grace, University of Southampton, Education School, Southampton, UK. Email:

M.M.Grace@soton.ac.uk (corresponding author)

Yeung Chung Lee, Hong Kong Institute of Education, Department of Science and Environmental Studies, Hong Kong, China. Email: yclee@ied.edu.hk

Roman Asshoff, University of Münster, Centre for Didactics in Biology, Münster , Germany. Email: roman.asshoff@uni-muenster.de

Anita Wallin, University of Gothenburg, The Department of Pedagogical, Curricular and Professional Studies, Gothenburg, Sweden. Email: Anita.Wallin@ped.gu.se

Word Count: 5945

\begin{abstract}
This paper focuses on the views of 16-17-year-old science students from England, Germany, Hong Kong and Sweden on whale hunting, and their perceptions of the views of their international counterparts. The students were all provided with the same decision making task, discussed the issue in small groups and then presented their views on video, which were shared with their counterparts. The findings show that the decision making task served to deepen and modify students' views across all nationalities, and the students generally valued and learned from the sharing of views with students of the same age from around the world. However, an important discovery was that the German students' opinions often ran counter to those from the other three locations, and the paper cautions against making broad-sweeping generalisations about students' views on socioscientific issues.
\end{abstract}

\section{Background}

The increasing focus on scientific literacy in the science curricula of many countries has led to a greater emphasis on students being able to make evidence-based evaluations and decisions (e.g. EACEA, 2011). However, this does not always prove easy in the classroom. Difficulties are particularly apparent when tackling socioscientific issues (SSIs), which are complex in nature and where there is not necessarily one 'correct' answer (Sadler et al, 2007). Such controversies include aspects of uncertainty and risk and raise hard, emotional questions, referred to by Simonneaux \& Simonneaux (2009) as socially acute questions (SAQs). Students need the opportunity to discuss such issues, and relate these arguments to their own values and beliefs (Oulton et al, 2004). Osborne et al. (2001) posited that changing one's thinking is an indication of good quality argument and this is only possible if there are opportunities to externalise that thinking, and expose one's beliefs to scrutiny by others. This can only take place effectively by individuals engaging in a sharing of views through some form of discussion.

SSIs are a very real part of science, and an ability to engage in decision making about SSIs is an important part of active citizenship. Scientists themselves are often involved in crisis management situations involving SSIs, where urgent decisions and actions have to be taken with insufficient time to accumulate sufficiently reliable knowledge about the issue (Soulé, 1995; Grace and Hare, 2008). They have to rely on a combination of limited information, intuition and their own creative skills, and this process often runs counter to their scientific training. They need to strike a balance between applying a rigid scientific approach to a 
problem, and taking into account the socioeconomic and cultural frames of reference, which inevitably impinge upon decision-making about SSIs. Similarly, someone who is not necessarily a professional scientist, but perhaps for example, a lay member of a group convened to make decisions about a local SSI, needs to have a degree of scientific literacy to better appreciate the complexity of the issue.

This research builds on extant studies which show that decision making discussions between students can modify their thinking and their views about controversial SSIs. There have been a few recent studies demonstrating the positive value gained from communication between students from different national and cultural backgrounds (e.g. Morin et al, 2013; Zeidler et al, 2002). This study develops this sharing of views approach further by examining the comments made by students in four countries on the views of their international counterparts. We used an approach to teaching about SSIs based on pedagogic practices described in the literature which enhance students' ability to make informed decisions about SSIs through discussion. These practices include the utilization of metacognitive strategies such as reflective thinking to integrate multiple perspectives (Zeidler et al, 2002), integration of knowledge acquisition, argumentation and personal value identification (Lee, 2007), group discussion using a prescribed decision-making framework (Grace, 2009), and confronting students with opposing arguments through class discussions to clarify their thoughts (Simonneaux, 2001).

The same approach was applied in four countries, and this article evaluates the study's 'cross-cultural' efficacy so that other practitioners might adopt the approach in their own teaching. 16-17-year-old science students in England, Germany, Hong Kong and Sweden took part in group decision making discussions about whaling (the hunting of whales) - a wellknown international and controversial SSI. Biological conservation is a precondition for sustainable development (Solbrig, 1991), and whale conservation is a particularly emotive issue involving some tough decisions about what and how to conserve. Conservation management programmes depend on an understanding of the biology of the organisms concerned and how they interact with their surrounding environment, but as with all SSIs, politics, economics and cultural aspects also play an important role in this decision-making process. Environmental issues are thus socially constructed and some professional biologists believe that cultural values are in fact more important than biological factors in deciding conservation priorities (Spellerberg, 1996).

Values relating to conservation issues can be incompatible between, and even within different cultural groups. A high-profile international example of this is the Inuit contention that they should continue whaling on the grounds that it is an intrinsic part of their culture. Hamazaki \& Tanno, (2001) reported that the public in non-whaling countries disapproved of whaling, whereas those in whaling countries generally approved. Other surveys also indicate that preferences vary between different cultures (e.g. Kellert, 1993) and there is a widespread belief that non-industrial communities, such as North American Indian societies, often possess a kind of deep-seated 'ecological wisdom', with a mutual dependence and equitable status of humans and other species. However, Kellert (1996) reported that people from less industrialised societies actually often have a less positive attitude towards wildlife, view ing it with fear and hostility.

The work described here considers how cultural differences might affect the way science students engage with conservation decision making. We are using the term 'culture' in the loose sense of the existing set of norms, values and practices that characterise a group of 
people. This is in line with Rohner's description of culture as a learned system of beliefs about the manner in which people interact with their social and physical environment, shared among an identifiable segment of a population, and transmitted from one generation to the next (Rohner, 1984). Understanding how students approach the task, what values they draw upon and how they interact with each other will help education researchers and practitioners design appropriate lessons involving SSIs and professional development programmes for science teachers. The four national environments differ in many respects. For example, the population density in Hong Kong is 60 times greater than England, and 800 times greater than Sweden. The population of Hong Kong is predominantly Chinese. With its history as a British colony, and now a 'Special Administration Region' of China, Hong Kong has been widely regarded as a 'melting pot' of the East and the West, whose values tend to be affected by both the Chinese traditional culture of eating wild game and the growing awareness of wildlife conservation. In Sweden the concept of 'Allemansrätt' (all peoples' right to move freely on uncultivated private land) is part of that country's cultural heritage, a comparatively alien idea to citizens in the other countries. Germans are often associated with a strong ecological awareness and the country leads in environmental protection in Europe, for example in terms of reducing the ecological footprint by waste recycling or reducing of $\mathrm{CO}_{2}$ emissions.

The overall purpose of the study was to see how the students in the four cultural settings responded to the whaling decision making activity, and to explore the value of providing students with the opportunity to hear the views of their international counterparts. There were three main research questions:

1. Do students from different international locations exhibit different views about a global SSI while engaging in the same decision making process?

2. Do cultural factors play an explicit part in this decision making?

3. What is the value in students sharing their views with their international counterparts?

\section{Methods}

Ethical approval was obtained from each of the researchers' institutions prior to the study. Science classes of 16-17-year-olds in co-educational schools in England ( 8 females; 8 males), Germany (16 females; 8 males), Hong Kong ( 9 females; 11 males), and Sweden ( 8 females; 12 males), were engaged in the same decision-making task about whaling. The students in each class were from mixed socioeconomic and ethnic backgrounds, so they were not representative of any particular social group. We recognize that these are small samples and the study is very much an initial exploration of the possibility that students in different countries provide different overall responses. The small sample size meant that testing for statistical differences between individual students' pre and post-test responses would yield less useful data than examining their collective responses.

All classes carried out the tasks in their normal science classroom settings in small peergroups, i.e. in groups that they usually worked in during their science lessons. Their tasks were divided into the following stages:

1. Students were introduced to the issue of whaling by means of a short video ( 10 minutes) depicting the lives of members of a small remote community which depends on whaling;

2. As a pre-test, students individually (without conferring) responded to the question 'What do you think should be done about whaling, and how?' (10 minutes). These responses were then immediately collected by the teacher/researcher as a true preactivity record. 
3. Students were placed in peer groups of 4-7 individuals and each member was asked to read at least two background information documents, lasting a total of about 20 minutes. These documents were fairly short extracts or summaries of views and factual information about whaling collated from a range of sources. The text was carefully selected or created to be appropriate for students of this age, ability and background. The documents were:

'Whales and whaling' - an overview of the biology of whales, the main reasons for whaling, and its history (read by all students); 'Greenpeace's views on whaling'; 'The Japanese Government's position on whaling'; 'Whale welfare' (e.g. methods of killing whales, and animal welfare issues); 'Aboriginal subsistence whaling'; 'The role of whales in aquatic ecosystems'; 'Is whale meat safe to eat?'; 'Intelligence of whales'; 'Some personal views on whaling' (from internet blogs, etc).

4. Using a decision-making framework (based on models successfully implemented previously by Lee, 2007, and Grace, 2009), students spent 40 minutes considering and noting down the following, with one student acting as a scribe for each group:

i) the stakeholders who might be affected or concerned, and what their views might be;

ii) the possible options/ ways forward to solve the issue, and for each option, fully discuss the pros and cons;

iii) the important criteria the group is using to make a decision;

iv) what further information might be needed to make a decision;

v) the group decision/solution

vi) reflection on the decision-making process

5. As a post-test, students wrote down their own individual views in the same manner as the pre-test described above (10 minutes). Students were also asked to write down what factors might influence global students' decision making about whaling (5 minutes).

6. Representatives from each group presented their group view and decision to the whole class. These were video-recorded by the English, Hong Kong and Swedish groups (5-10 minutes per group).

7. The video-recorded presentations were subtitled in English, and shown to the groups in other countries. In Sweden, Germany and England, students wrote down their thoughts about perceived similarities and differences between their own class's views and those of their international counterparts, their views about cultural impacts on decision making about whaling, and the extent to which they valued this experience of sharing points of view. In Hong Kong students did not write down their responses but students were selected randomly to attend three small post-lesson group interviews, and their comments were recorded.

The whole sequence of activities spanned two or three lessons, depending on the lesson length in each school. The pre and post-test questionnaires were no more than a week apart, and the video-watching sessions were shown no more than a month after the original intervention.

We wanted to make the purpose of our research explicit to the students from the start, and explained that we were interested in what students their age thought about SSIs such as whaling, and that this information would help us improve curriculum materials in this area.

For consistency, the authors (as researchers) administered the tasks, and an attempt was made to elicit students' true feelings about the issues by reinforcing the message to students throughout the intervention that there were no 'correct' answers, that their responses would 
not affect their grades, that their responses would remain anonymous, and that they could withdraw from the activities at any time. The activities were carried out in students' own native languages, and the written responses were translated into English by the researchers. The English and Swedish video presentations were given in English (and subtitled in Cantonese by the researcher from Hong Kong), the Hong Kong presentations were given in Cantonese and subtitled in English for the other students. The German students carried out the activities later than the others and so were unable to share their video with their counterparts. Consequently, there are no comments about the German views.

Student decisions, justifications for these decisions, and possible associated cultural influences on their decision-making processes were coded and categorised. The researchers scrutinised the written responses from their own students, and subjected this empirical material to an inductive analysis (Johnson \& Christensen, 2004) through a repeated process of annotating and re-annotating the scripts, interspersed with discussions and sharing of examples until agreed themes emerged.

\section{Findings and discussion}

There are very few surveys of national opinions on whaling, but the limited data indicates that attitudes towards whaling vary between countries. Freeman \& Kellert (1992) surveyed attitudes of people in six countries on the acceptability of whaling. Two were whaling countries (Japan and Norway) and four non-whaling countries (Australia, England, Germany and the United States). In response to a question about being 'opposed to whale hunting under any circumstances', respondents in the non-whaling countries were significantly more opposed to whaling than those in whaling countries. Among the non-whaling countries, $60.0 \%$ of the Australian respondents were opposed to whaling under any circumstances, followed by the German (54.3\%), American (48.4\%) and English (43.1\%) and respondents. Freeman and Kellert's finding that the German general public are more 'anti-whaling' than the English general public is mirrored by the German and English students' responses in this study (i.e. at pre-test in Figure 1). However, the anti-whaling sentiment in both countries appears to be less prominent among these science students of today than among their general populations twenty years ago. This difference could be linked to a change in views over the years or to the students being distinctive in all having had some previous science training.

It could be argued that the relatively high number of females in the German class might skew the results, as there is some evidence that females are more anti-whaling than males in Germany. For example, in a recent survey of a thousand adults in both Germany and the UK, significantly more females than males in Germany strongly disagreed with commercial whaling, whereas there was no significant difference among UK men and women (ORC International, 2014). However, in the present study pre-test, there was there was no discernable gender difference, with $25 \%$ of the German males and $25 \%$ of the females taking an anti-whaling stance.

\section{Students'views about whaling}

Inductive analysis of the students' decisions on what approach should be taken to whaling resulted in the emergence of six discernible categories:

1. Subsistence whaling. Accepting whaling if it is necessary to fulfil human needs, e.g. survival of aboriginal people who rely on whale meat as their main food source, or see whaling as an indispensable part of their culture legitimizing trading of whale meat as a source of personal or national income. 
2. Regulated whaling. Imposing restrictions on whaling in general, e.g. some kinds of quota systems.

3. Humane whaling. Killing whales only in a humane way.

4. Commercial whaling. Legitimizing trading of whale meat as a source of personal or national income; whaling is considered as a normal hunting activity like fishing.

5. Research whaling. Allowing the catching or killing of whales for research purposes.

6. Anti-whaling. Disapproving of any form of whaling under any circumstances.

With the exception of 'anti-whaling', none of these categories is mutually exclusive, that is, students might have opted for one or a combination of these as their decisions. Figures 1 and 2 show the comparison of students' decisions at the pre-test and post-test stages (ie before and after the intervention) in each country. A striking finding was that the pre and post-test changes for the German students were quite the reverse of the rest. Their support for antiwhaling increased, and their support for all the other categories decreased. This opposing trend among the German students is discussed later. The data shows that the large majority of students at pre-test, and all students at post-test in England, Hong Kong and Sweden, took an anthropocentric view by advocating subsistence whaling if it meant that a community depended on whaling for human survival. However, the German students' views about subsistence whaling remained fairly stable between pre and post-test. Very few students in England, Hong Kong and Sweden took an anti-whaling stance in the pre-test, and after discussion this was reduced to zero among all students in all three locations. Post-test, these three groups also showed an increase in advocating some sort of regulation or control of whaling to ensure that whale populations will not be adversely affected. Again, the German students' responses were very different; $24 \%$ were anti-whaling at pre-test, rising to $35 \%$ in the post-test, indicating that the intervention had the reverse effect on them compared to the other nations.

Prior to discussions, Hong Kong and German students were noticeably the most predisposed towards regulated whaling and humane whaling respectively. After the discussions, more English, Hong Kong and Swedish students were generally supportive of regulated, humane, commercial and research whaling, i.e. they had become more pro-whaling across categories, and in general responses from each of these three locations followed a similar trend. This reflects findings from Grace (2009) that structured decision making discussions about other conservation issues results in students moving towards an increased acceptance of culling. For both commercial and research whaling, Hong Kong students were more accepting than Swedish students, and Swedish students were more accepting than English students. One may speculate that this marked increase in approval of commercial and scientific whaling among Hong Kong students was related to the unusual sociopolitical and economic context of Hong Kong where 'East meets West', where people are through necessity more inclined to be pragmatic and tolerant of diverse viewpoints. Despite the lack of a political system comparable to the western-style democracy practised in England, Germany and Sweden, Hong Kong people are used to resolving problems by consensus. Moreover, economic development has been a prime concern of Hong Kong, which has grown into an international financial hub. This may explain why Hong Kong students have become more accepting of commercial whaling compared with their counterparts in the other three places after the activity. A corollary of this is that Hong Kong students may be more ambivalent about taking sides on controversial issues, especially those with economic implications. The following extracts from Hong Kong group interviews provide some support for this hypothesis: 
'We do not think we should be too assertive to make our decision, as making a wrong decision is more a loss than a gain.'

'We think we can find seek a balance such that nobody will be disadvantaged.'

However, whether the unique politico-cultural and economic context of Hong Kong has exerted a covert influence on students' decisions has yet to be explored by further studies.

Figures 1 and 2 about here.

\section{Students' perceived reasons for differences in views}

So what did thee students think about their counterparts' views? Table 1 shows students' thoughts on the similarities and differences between their own class's views on whaling and the views presented on video by their international counterparts. By reviewing the students' videos and written responses, the researchers were able to check whether these views were actually correct or incorrect, and they are categorised this way in the table.

\section{Table 1 about here}

In terms of learning, it is clear from the incorrect reporting shown Table 1 that some students misunderstood or forgot the views of their counterparts, or perhaps they weren't always being sufficiently attentive. However, most reports about the views of others were accurate, and on balance this demonstrates the potential positive value of watching the videos. Watching the presentations also served to provide some new perspectives on the issue which students were prepared to consider, such as the German students' appreciation of the Hong Kong students' idea about giving parts of the whale not required for research to aboriginal communities. Despite the fact the some of their views may not be supported with strong justifications, those views reflect their impression of their counterparts' arguments. For example, 'They think more deeply than us.' 'They have a less balanced view of the argument'. The reasoning underlying these rather judgmental views are worthy of further exploration as they have potential to reveal the impact of this kind of cross-cultural exchange among different cultural groups.

\section{Students' perceptions about the role of cultural influences on decision-making}

After watching the videos, students were asked to write down what 'cultural' aspects they thought impacted on their own and their counterparts' decision making about whaling. A broad range of factors were suggested across the four groups, including political, philosophical, geographical, educational and historical factors, and all groups cited 'cultural' aspects an influential factor. We did not define the use of 'culture', but no students queried the meaning and we presumed that they were referring to culture in a general sense which includes social customs, laws, standards and traditions, etc. Results are shown in Table 2. Some responses indicated misconceptions about people in the other locations. For example, some English and Swedish students were under the misapprehension that Hong Kong is near to Japan (it's actually about 2000 kilometres away), and therefore they share similar cultural values and practices. Some English students commented that Sweden was recently a whaling nation (possibly mistaken for Norway?). So their logic was that these citizens could empathize with those in whaling nations. It was also noteworthy that in responding to the question about possible cultural aspects, the Hong Kong students more readily commented on 
their own cultural influences. For example:

'Hong Kong people are not so assertive, as making a wrong decision is more a loss than gain. We have some typical Chinese characteristics of and tend to be a bit mild - and do not like to displease anyone.'

'...like Golden Coin Terrapin in Hong Kong - traditionally eaten but now prohibited.'

English and Swedish students only commented on possible cultural influences in the other countries, possibly not particularly recognising their own cultural identities.

\section{Table 2 about here}

The value of exchanging video presentations

Students were also asked about the 'usefulness' of watching each other's video presentations. Responses are shown in Table 3.

\section{Table 3 about here}

The majority of students in all countries considered the exchange of video presentations useful in some respect, and representatives from all groups mentioned the value of seeing things from a different or wider perspective. Students gleaned some additional ideas about whale conservation from the other groups. For example, the Swedish students first heard from the Hong Kong students that aboriginal communities might actually benefit from commercial whalers; the English students first learned from the Hong Kong students that breeding whales might be a useful conservation measure; the Hong Kong students first heard from the English students about the idea of accepting whaling as long as nothing is wasted; and the English students first heard from the Swedish students about the notion of commercial and scientific whaling being mutually supportive. Students were sometimes more struck by the similarities than the differences in views, as exemplified by the comment from an English student: 'It shows how people living thousands of miles away in other countries can have almost identical views as you.'

\section{Conclusions and Implications}

Relatively few studies have been carried out comparing socioscientific decision making between different countries and cultures, but these have already begun to reveal the existence of similarities and differences. Zeidler et al (2013) compared the approaches taken by students from five countries (Jamaica, South Africa, Sweden, Taiwan, and the United States) in making decisions about the distribution of scarce medical resources. Their results indicated a high degree of congruence in the way the students framed their reasoning on this socioscientific issue and in their justifications for their epistemological beliefs. Morin et al (2013) reported an enhanced level of reasoning among French and Australian pre-service teachers when they engaged in on-line discussions about a science-based environmental issue.

However, Lee and Grace (2012) implemented a cross-contextual study comparing decision making on avian flu by students from Hong Kong and mainland China. They found differences between the students in the two settings with respect to their reasoning perspectives, evidence perceived to be useful to gather, decision making criteria, and postactivity decisions. This raises the question of how reliable is it to generalise about students' 
approaches to SSIs. If the present study had been limited to the student groups from England, Hong Kong and Sweden, we would have found many similarities. After the intervention, most students in England, Hong Kong and Sweden became more sympathetic towards subsistence whalers who traditionally rely on whales as their staple food, and gave high priority to protection of whales through careful regulation of hunting. Consequently, none of these students took a completely anti-whaling stance following the discussions. They wanted to avoid whales becoming endangered, but they accepted whaling under certain conditions. This dualism of adopting both anthropocentric, and biocentric or ethical values appeared to characterize the reasoning of most students, a phenomenon which apparently transcended cultural boundaries. However, this picture is different in the German sample. Following the intervention, all German students disapproved of commercial and scientific whaling. Their initial positive attitude towards regulated whaling declined in favour of an anti-whaling position. The German students additionally stated that there were aesthetic reasons for not approving of whaling and that whaling in general is immoral and cruel.

The German students were thus more sceptical towards whaling than the students from the other nations following the intervention. Reasons for this stark difference would require further investigation, but some reports (e.g. European Commission, 2008) indicate that German citizens have a relatively highly developed environmental consciousness. Kellert (1993) underlined this impression in a study about attitudes towards wildlife in the United States, Japan and Germany. Using interview data from a total of 1484 German individuals, he showed Germans to have a strong affection and concern towards animals and nature in general. He also reported that Germans had an exceptionally high moralistic (and 'green') attitude towards wildlife compared to the Americans and Japanese. German participants in the current study clearly expressed an opposition to the exploitation of animals.

Schleicher (1995) reported that environmental awareness and education developed earlier in Germany compared to other EU member states. Western Germany has a long tradition of ecological and 'alternative' movements. In the 1980s there was strong resistance to nuclear power and strong national lobbying over the problem of 'Waldsterben' (forest dieback). The issue of whaling, seen as an ecological problem by the German students, might therefore fall on fertile ground. Environmental concern seems to be deeply rooted in German society and we argue that these ecological concerns in general might be a reason for the strong attitudes of German students towards whaling. Menzel \& Bögeholz (2009) showed that when 16-18-yearold German students discussed biodiversity issues, they tended to argue in an ecological way and that they had difficulties in integrating the ecological, economic, and social aspects of a topic, probably because it is not taught in school. The authors also found that students who concentrated on ecological aspects showed difficulties in developing empathy and solidarity with impoverished people, when judging a dilemma. However, in the present study there is no evidence that the German students found this any more difficult than their international counterparts.

To be clear, we are not singling out the German students as being unique in their views; it is possible that students from other countries around the world would align their views more closely with the German students than the others, and we therefore caution against making international generalisations about students' approaches SSIs without further investigation across a wider sample within a cultural group and a much wider range of cultures.

It is noticeable that students did not use much scientific/biological data and evidence (such as changes in whale populations over recent decades) to support their arguments, and this is 
consistent with findings from Bell and Lederman (2003) that the nature of science (such as the tentativeness of scientific knowledge) does not figure prominently in students' decision making about SSIs. This implies that to further develop students' ability of reasoning and decision making about controversial SSIs to a more sophisticated level, students need to develop their understanding of the nature of science and scientific knowledge and how these connect with SSIs (Kolsto, 2001).

Although this study only focused on whaling, the approach could be used to good effect across a range of SSIs. This activity clearly resulted in modified views across all four groups of students. However, the above analysis implies that culture may be an important factor that affects students' reasoning and decision making by influencing values and the way they negotiate different viewpoints in coming to a decision. Subject to confirmation by further research based on larger samples, the present findings have implications for the discussion of SSIs, especially global ones which entail international collaboration. The diversity of students' viewpoints observed in this study is reminiscent of the diverse or conflicting views of different countries or cultural groups on controversial issues. Since the resolution of many controversial SSIs such as the use of antibiotics, depletion of fossil fuels, climate change and biodiversity conservation requires concerted international efforts, it makes a lot of sense for students from different localities to establish some mutual understanding, so that in future they could communicate and collaborate with each other in tackling these issues more effectively. The findings will hopefully also help curriculum developers and teacher trainers design materials and programmes to promote decision making about conservation issues, and this provides a case study and model for teachers who wish to promote among their students an awareness of how their counterparts in other parts of the world feel about and respond to such issues. On a final note, although sharing video-recordings served its purpose, we would recommend taking it a step further by replacing the video-recording with synchronous video-conferencing to further engage students with each other's views and avoid misinterpreting their views, although the different international time zones could sometimes hamper this approach.

The authors would be very happy to provide all documents used in this study and the source material to anyone interested.

\section{Acknowledgements}

The authors would like to thank all the schools, teachers and students who took part in this study, and in particular Claudia Liesenkötter and Nicola Jefferies for giving so generously of their time in helping with the data collection and preliminary evaluation.

\section{References}

Bell, R. L. \& Lederman, N. G. (2003) Understandings of the nature of science and decision making on science and technology based issues. Science Education, 87, 352-377.

European Commission (2008) Attitudes of European citizens towards the environment. Special EUROBAROMETER 295/Wave 68.2 - TNS Opinion \& Social.

EACEA (Education, Audiovisual and Culture Executive Agency) (2011). Science Education in Europe: National Polices, Practices and Research. Brussels: Eurydice 
Freeman, M.M.R., \& Kellert, S.R. 1992. Public Attitudes to Whales - Results of a SixCountry Survey. Edmonton, AB: Canadian Circumpolar Institute, University of Alberta.

Grace, M. and Hare, T. (2008) How conservation scientists work. School Science Review, 90 (330), 47-52

Grace, M. (2009) Developing high quality decision-making discussions about biological conservation in a normal classroom setting. International Journal of Science Education, 31 (4), 551-570

Hamazaki, T. and Tanno, D. (2001) Approval of whaling and whaling-related beliefs: Public opinion in whaling and nonwhaling countries. Human Dimensions of Wildlife, 6, 131-144. Johnson B. \& Christensen L. (2004). Educational research: Quantitative, qualitative, and mixed approaches (2nd edition). Boston: Pearson Education, Inc.

Kellert, S.R. (1993) Attitudes, Knowledge and Behavior Toward Wildlife Among the Industrial Superpowers: United States, Japan and Germany, Journal of Social Issues, 49(1), 53-69

Kellert, S. R. (1996) The value of life: Biological Diversity and Human Society. Washington D. C.: Island Press

Kolstø, S. D. (2001). Scientific literacy for citizenship: Tools for dealing with the science dimension of controversial socioscientific issues. Science Education, 85, 291-310.

Lee, Y. C. (2007) Developing decision-making skills for socio-scientific issues. Journal of Biological Education, 41(4), 170-177.

Lee, Y. C., \& Grace, M. (2012). Students' reasoning and decision making about a socioscientific issue: A cross-context comparison. Science Education, 96, 787-807.

Lincoln, Y., \& Guba, E.G. (1985). Naturalistic Inquiry. Beverly Hills, CA: Sage.

Menzel, S., Bögeholz (2009) The Loss of Biodiversity as a Challenge for Sustainable Development: How Do Pupils in Chile and Germany Perceive Resource Dilemmas? Research in Science Education 39:429-447.

Morin, O., Tytler, R., Barraza, L., Simonneaux, L. \& Simonneaux, J. (2013) Cross cultural exchange to support reasoning about socio-scientific sustainability issues, Teaching Science, 59(1), 16-22.

Oulton, C., Dillon, J., \& Grace, M. M. (2004) Reconceptualizing the teaching of controversial issues. International Journal of Science Education, 26(4), 411-423.

ORC International (2014) Whaling Study: United Kingdom and Germany, Available at: http://www.google.co.uk/url? sa=t\&rct=j\&q=\&esrc=s\&source=web\&cd=2\&ved=0CCoQFjA B\&url=http $\% 3 \mathrm{~A} \% 2 \mathrm{~F} \% 2 \mathrm{Fuk}$. whales.org\%2Fsites \%2Fdefault $\% 2 \mathrm{Ffiles} \% 2 \mathrm{~F} 2014$-whalingsurvey-ukgermany.pdf\&ei=bXVPVaXtJ8aP7AabtIGgAg\&usg=AFQjCNGYyP1Es1E3VvpCYpB2ttDa3xOqg\&sig2=zHEcWn6lvLYZ39KjdJlCGg (Accessed: 9 May 2015) 
Osborne, J., Erduran, S., Simon, S. and Monk, M. (2001b) Enhancing the quality of argument in school science. School Science Review, 82, 301, 63-70.

Ratcliffe, M, and Grace, M. (2003). Science education for citizenship. Maidenhead, Philadelphia: Open University Press.

Rohner, R. P. (1984) Toward a concept of culture for cross-cultural psychology. Journal of Cross-Cultural Psychology, 15, 111-138

Schleicher, K. (1995): Trends and Current State of Environmental Education in Germany. In: Bos, W. and Lehmann, R.H.: Reflections on educational achievement. Münster-New York, Waxmann: 230-255.

Sadler, T. D., Barab, S. A., \& Scott, B. (2007). What do students gain by engaging in socioscientific inquiry? Research in Science Education, 37, 371-391.

Simonneaux, L. (2001). Role-play or debate to promote students' argumentation and justification on an issue In animal transgenesis. International Journal of Science Education, 23(9), 903-927.

Simonneaux, L., and J. Simonneaux (2009) Students' Socio-scientific Reasoning on Controversies from the Viewpoint of Education for Sustainable Development, Cultural Studies of Science Education 4 (3), 657-687.

Solbrig, O. T. (1991) The roots of the biodiversity crisis. Biology International, 23, 5-13 (International Union of Biological Sciences)

Soulé, M. (1995) The social siege of nature. In M. Soule and G. Lease (eds.), Reinventing Nature? Responses to Postmodern Deconstruction, pp 137-170. Washington: Island Press

Spellerberg, I. F. (1996) Conservation Biology. Harlow: Longman

Wulfmeyer, M. (2006): Bildung für nachhaltige Entwicklung im globalen Kontext. Das Beispiel Namibia. Berlin.

Zeidler, D., L., Walker, K. A., Ackett, W. A., and Simmons, M. L. (2002). Tangled up in views: Beliefs in the nature of science and responses to socioscientific dilemmas. Science Education, 86, 343-367

Zeidler, D.L., Herman, B.C., Ruzek, M., Linder, A. and Shu-Sheng, L. (2013) Cross-Cultural Epistemological Orientations to Socioscientific Issues, Journal of Research in Science Teaching, 50 (3), 251-283 
Table 1. Students' responses to the question: What are the similarities/differences between your class's views and those of your counterparts in the other countries? These are the items mentioned by more than $10 \%$ of the students and they are presented in rank order. (NB. The German students did not video their presentations and did not comment on the Swedish video).

\begin{tabular}{|c|c|c|c|}
\hline & $\begin{array}{l}\text { Thoughts about the views } \\
\text { of Swedish students }\end{array}$ & $\begin{array}{l}\text { Thoughts about the views } \\
\text { of English students }\end{array}$ & $\begin{array}{l}\text { Thoughts about the } \\
\text { views of Hong Kong } \\
\text { students }\end{array}$ \\
\hline $\begin{array}{l}\text { Responses } \\
\text { given by } \\
\text { Swedish } \\
\text { students }\end{array}$ & & $\begin{array}{l}\text { Similarities/differences } \\
\text { reported correctly: } \\
\text { - They are less keen on } \\
\text { regulating whaling than } \\
\text { us }(65 \%) \\
\text { Similarities/differences } \\
\text { reported incorrectly: } \\
\text { None }\end{array}$ & $\begin{array}{l}\text { Similarities/differences } \\
\text { reported correctly: } \\
\text { - They support } \\
\text { subsistence whaling } \\
\text { (65\%) } \\
\text { - They support } \\
\text { commercial \& } \\
\text { scientific whaling } \\
\text { more than us (15\%) } \\
\text { They think about } \\
\text { industry \& } \\
\text { economics rather } \\
\text { than caring about } \\
\text { whales (10\%) } \\
\text { They don't support } \\
\text { humane whaling as } \\
\text { much as us (10\%) } \\
\text { Similarities/differences } \\
\text { reported incorrectly: } \\
\text { They support } \\
\text { They support the } \\
\text { same views as us } \\
\text { (25\%) } \\
\text { They know more } \\
\text { about whaling than } \\
\text { us (15\%) }\end{array}$ \\
\hline $\begin{array}{l}\text { Responses } \\
\text { given by } \\
\text { English } \\
\text { students }\end{array}$ & $\begin{array}{l}\text { Similarities/differences } \\
\text { reported correctly: } \\
\text { - } \quad \text { They support } \\
\text { subsistence whaling } \\
\text { (31\%) } \\
\text { - They are keener on } \\
\text { restricting commercial } \\
\text { whaling than us (25\%) } \\
\text { - They are keener on } \\
\text { quotas than banning } \\
\text { whaling }(25 \%)\end{array}$ & & $\begin{array}{l}\text { Similarities/differences } \\
\text { reported correctly: } \\
\text { - They support } \\
\text { commercial aspects } \\
\text { of whaling more than } \\
\text { us }(57 \%) \\
\text { - They support } \\
\text { subsistence whaling } \\
\text { (31\%) } \\
\text { - They support quotas } \\
\text { more than us }(31 \%)\end{array}$ \\
\hline
\end{tabular}




\begin{tabular}{|c|c|c|c|}
\hline & 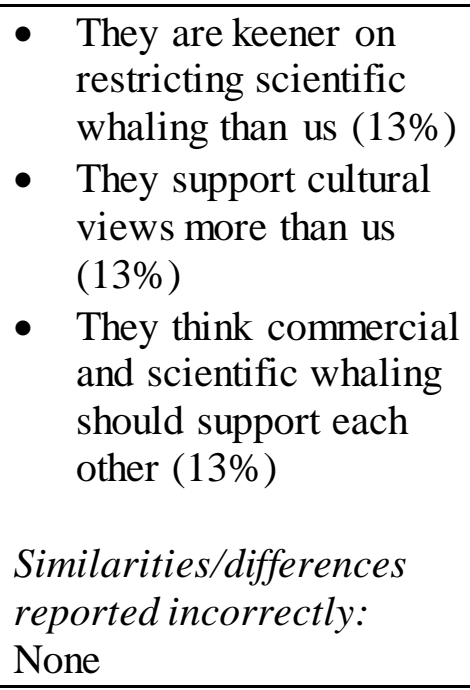 & & $\begin{array}{l}\text { - } \begin{array}{l}\text { They had the idea of } \\
\text { breeding whales } \\
(13 \%) \\
\text { - They support } \\
\text { research quotas more } \\
\text { than English students } \\
(13 \%)\end{array} \\
\text { Similarities/differences } \\
\text { reported incorrectly: } \\
\text { None }\end{array}$ \\
\hline $\begin{array}{l}\text { Responses } \\
\text { given by Hong } \\
\text { Kong students }\end{array}$ & $\begin{array}{l}\text { Similarities/differences } \\
\text { reported correctly: } \\
\text { - They value animal } \\
\text { 'rights' and humane } \\
\text { whaling more than us } \\
\text { (ie have a more } \\
\text { biocentric view) } \\
\text { - They are less } \\
\text { predisposed to whaling } \\
\text { than us } \\
\text { - We prefer to find a } \\
\text { solution that makes } \\
\text { everyone happy } \\
\text { Similarities/differences } \\
\text { reported incorrectly: } \\
\text { None } \\
\text { Reported } \\
\text { similarities/differences } \\
\text { unsubstantiated: } \\
\text { They have firmer and } \\
\text { more consistent views } \\
\text { than us } \\
\text { They have a less } \\
\text { balanced view of the } \\
\text { argument than us }\end{array}$ & $\begin{array}{l}\text { Similarities/differences } \\
\text { reported correctly: } \\
\text { - They value animal } \\
\text { 'rights' and humane } \\
\text { whaling more than us (ie } \\
\text { they have a more } \\
\text { biocentric view) } \\
\text { - } \\
\text { Similarities/differences } \\
\text { reported incorrectly: } \\
\text { None } \\
\text { Reported } \\
\text { similarities/differences } \\
\text { unsubstantiated: } \\
\text { - We prefer to find a } \\
\text { solution that makes } \\
\text { everyone happy } \\
\text { They have firmer and } \\
\text { more consistent views } \\
\text { than us } \\
\text { They have a less } \\
\text { balanced view of the } \\
\text { argument than us }\end{array}$ & \\
\hline $\begin{array}{l}\text { Responses } \\
\text { given by } \\
\text { German } \\
\text { students }\end{array}$ & & $\begin{array}{l}\text { Similarities/differences } \\
\text { reported correctly: } \\
\text { - They approve of } \\
\text { aboriginal whaling more } \\
\text { than us }(70 \%)\end{array}$ & $\begin{array}{l}\text { Similarities/differences } \\
\text { reported correctly: } \\
\text { - They approve of } \\
\text { regulated, } \\
\text { commercial and }\end{array}$ \\
\hline
\end{tabular}




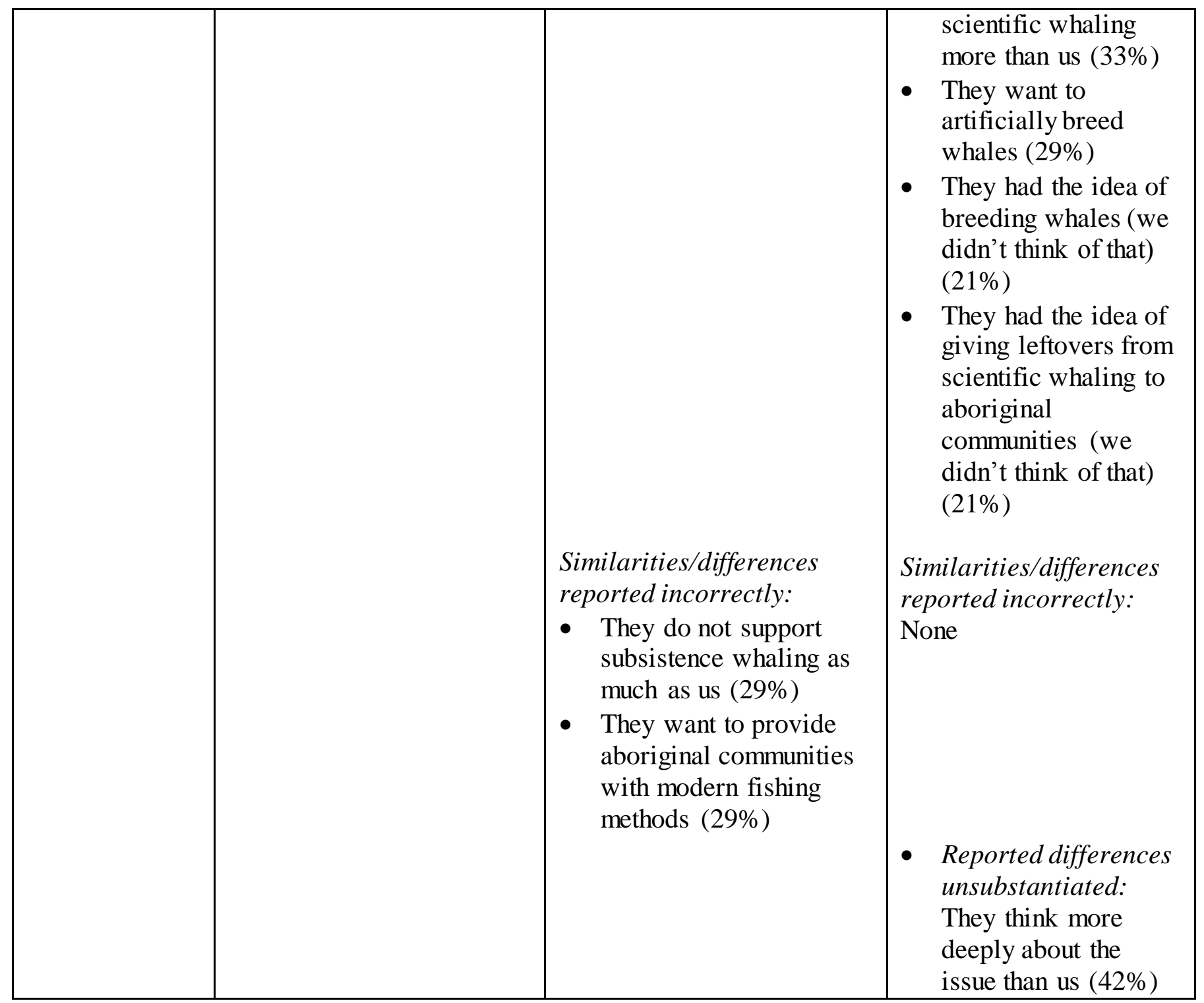


Table 2. Students' responses to the question: What cultural aspects (if any) do you think impact on your and your counterparts' decision-making about whaling? (after watching the videos)

\begin{tabular}{|c|c|}
\hline $\begin{array}{l}\text { Responses given } \\
\text { by Swedish } \\
\text { students }(\mathbf{n}=\mathbf{2 0})\end{array}$ & $\begin{array}{l}\text { - } 40 \% \text { (8) acknowledged cultural aspects have an impact } \\
\text { - } 30 \% \text { (6) indicated that Hong Kong students are affected by their close } \\
\text { relationship with Japan } \\
\text { 'I believe that the cultures affect your view on whaling (e.g. the student from } \\
\text { Hong Kong is more familiar with the Japanese culture of whaling).' } \\
\text { - } 20 \% \text { (4) mentioned that Sweden used to be a whaling nation which would } \\
\text { affect their views on whaling } \\
\text { - } 15 \% \text { (3) mentioned 'Asian' people possibly empathising better with whalers }\end{array}$ \\
\hline $\begin{array}{l}\text { Responses given } \\
\text { by English } \\
\text { students }(n=16)\end{array}$ & $\begin{array}{l}\text { - } 56 \% \text { (9) acknowledged cultural aspects have an impact } \\
\text { - } 31 \% \text { (5) indicated that Hong Kong students are affected by their close } \\
\text { relationship with Japan } \\
\text { - } 25 \% \text { (4) mentioned Hong Kong's close relationship with aboriginal } \\
\text { communities, so students empathise better with whalers } \\
\text { '...there are many tribes in China, which means that the people of HK would } \\
\text { agree with aboriginal whaling.' } \\
\text { - 'We all have different upbringings, morals, traditions, individual preferences.' }\end{array}$ \\
\hline $\begin{array}{l}\text { Responses given } \\
\text { by Hong Kong } \\
\text { students } \\
\text { ( } 3 \text { discussion } \\
\text { groups) }\end{array}$ & $\begin{array}{l}\text { - Hong Kong people do not wish to displease anyone } \\
\text { - The tradition of eating the Golden Coin Terrapin in Hong Kong } \\
\text { - 'Swedish students take an animal rights view. Maybe they encounter these } \\
\text { issues more often and so develop these views.' }\end{array}$ \\
\hline $\begin{array}{l}\text { Responses given } \\
\text { by German } \\
\text { students } \\
(\mathbf{n}=\mathbf{2 4})\end{array}$ & $\begin{array}{l}\text { - } 92 \% \text { (22) acknowledged cultural aspects have an impact } \\
\text { - } 8 \% \text { (2) said that Hong Kong students are most affected by the issue } \\
\text { - } 8 \% \text { (2) mentioned that Chinese people eat dogs and cats so eating whales } \\
\text { would not be surprising } \\
\text { - } 20 \% \text { (5) mentioned different 'feeding habits' and food types in different } \\
\text { countries } \\
\text { - } 8 \% \text { (2) mentioned that different countries have different attitudes towards } \\
\text { animals }\end{array}$ \\
\hline
\end{tabular}


Table 3. Students' responses to the question: Were the videos useful? If so, how?

\begin{tabular}{|c|c|}
\hline $\begin{array}{l}\text { Swedish } \\
\text { students' } \\
\text { responses } \\
(n=16)\end{array}$ & $\begin{array}{l}\text { - Yes } 50 \%(8) \\
\text { - Provides a different perspective } 25 \% \text { (4) } \\
\text { - Provides useful arguments } 19 \%(3) \\
\text { - } \text { Fun } 25 \%(4) \\
\text { - '...now I see whaling in many different ways and feel like I know more about } \\
\text { how I feel for it.' } \\
\text { - 'I think so: It has opened my mind for the culture of whaling, mostly negative.' } \\
\text { - 'Learn more how the world thinks about whaling.' } \\
\text { - 'I thought the Asians would be more positive to it, (don't know why...) so... } \\
\text { well, I guess the videos made me realise I was wrong.' }\end{array}$ \\
\hline $\begin{array}{l}\text { English } \\
\text { students' } \\
\text { responses } \\
(\mathbf{n = 2 0})\end{array}$ & $\begin{array}{l}\text { - Yes } 60 \%(12) \\
\text { - } \quad \text { Provides a different perspective } 60 \% \text { (12) } \\
\text { - 'It shows how people living thousands of miles away in other countries can have } \\
\text { - 'Blmost identical views as you. They had views we didn't think of.' } \\
\text { - 'Saw different ideas such as they [Hong Kong students] had the idea of breeding } \\
\text { whales which we never thought of.' }\end{array}$ \\
\hline $\begin{array}{l}\text { Hong Kong } \\
\text { students' } \\
\text { responses } \\
\text { (3 discussion } \\
\text { groups) }\end{array}$ & $\begin{array}{l}\text { - Yes (most students) } \\
\text { - 'After watching the presentation of the British students, I think we should make a } \\
\text { bigger effort to stop scientific whaling.' } \\
\text { - 'Yes, but need to see Japanese students' view too' } \\
\text { - 'Helps us make a more informed decision' } \\
\text { - 'Helps us to be objective' } \\
\text { - 'Gave me a wider perspective' }\end{array}$ \\
\hline $\begin{array}{l}\text { German } \\
\text { students' } \\
\text { responses } \\
(\mathbf{n}=\mathbf{2 4})\end{array}$ & $\begin{array}{l}\text { - } \quad \text { Yes } 79 \%(19) \\
\text { - No } 20 \%(5) \text { 'Because we have an opinion and do not change it.' } \\
\text { - } \quad \text { You gain insights in different cultures } \\
\text { - It is useful because you see how peers in different countries think about the topic. } \\
\text { - It is good because you have a better starting point for discussions } \\
\text { - The Videos should be shown to the responsibilities and politicians }\end{array}$ \\
\hline
\end{tabular}


Figure 1. Pre-test cross-national comparison of students' views: percentage of students stating which kinds of whaling are acceptable

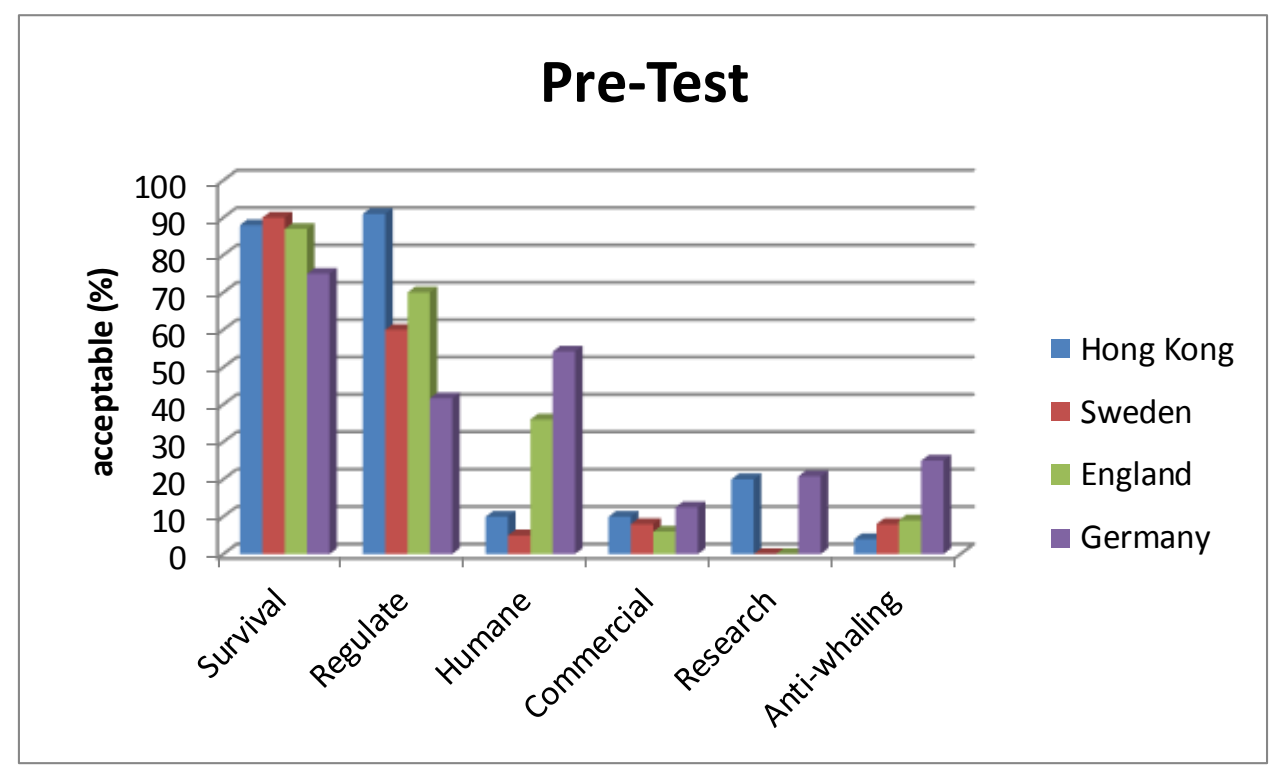

Figure 2. Post-test cross-national comparison of students' views: percentage of students stating which kinds of whaling are acceptable

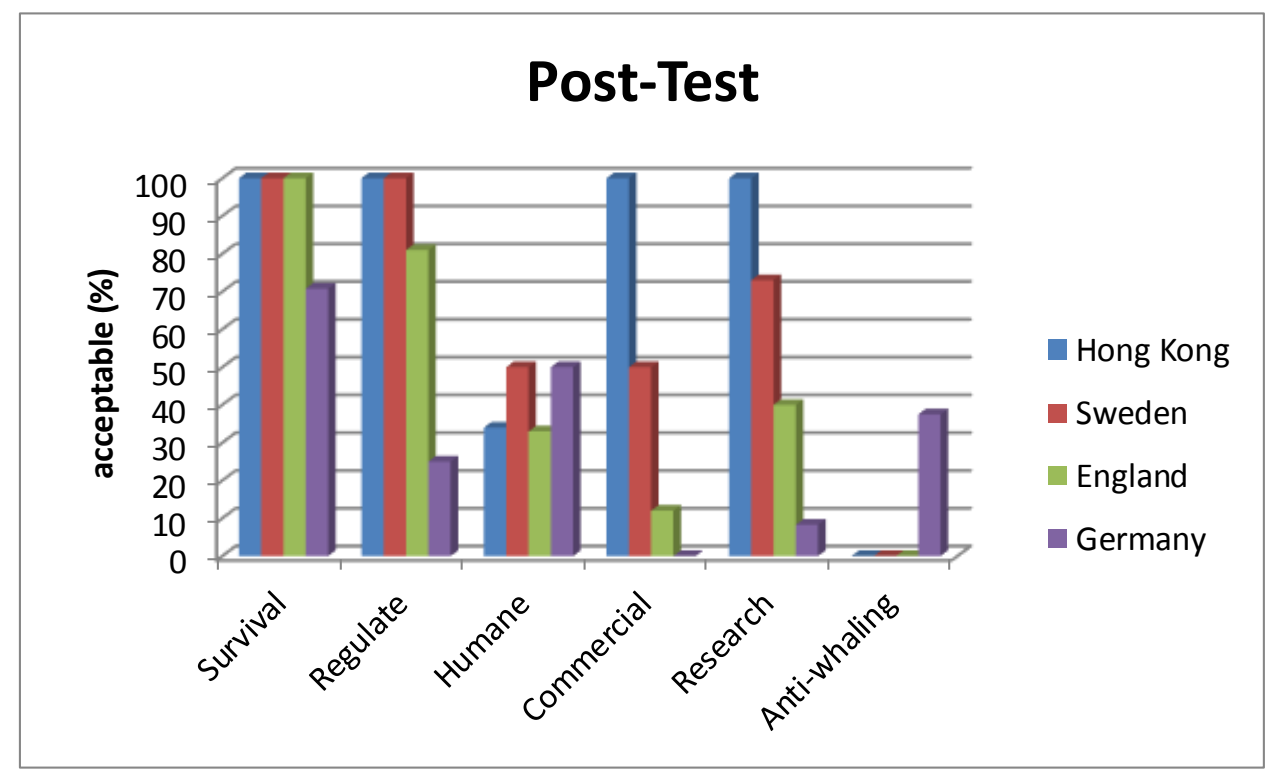

